\title{
Interleukin 28B Gene Polymorphisms and Epstein-Barr Virus-Associated Lymphoproliferative Diseases
}

\author{
Ela Akay Mauli Patel Tim Conibear Turren Chaggar Tanzina Haque \\ Department of Virology, Royal Free Hospital, London, UK
}

\begin{abstract}
Key Words
IL28B gene polymorphisms - Epstein-Barr virus . Acute infectious mononucleosis · Posttransplant lymphoproliferative disease $\cdot$ Viral load
\end{abstract}

\begin{abstract}
Objectives: Single-nucleotide polymorphisms (SNPs) near the interleukin (IL) 28B gene encoding a type III interferon (IFN- $\lambda$ ) are the most important genetic predictors of treatment response to hepatitis $\mathrm{C}$ virus $(\mathrm{HCV})$. This retrospective study was undertaken to determine any association between IL28B SNPs and the development of viraemia in Epstein-Barr virus (EBV)-driven acute infectious mononucleosis (IM) and post-transplant lymphoproliferative disease (PTLD). Methods: Genomic DNA extracted from plasma from 45 EBV seropositive controls and 46 acute IM, 23 non-PTLD (transplant) and 21 PTLD patients was tested by PCR for 2 SNPs within IL28B. EBV DNA levels were tested in IM and PTLD samples by a real-time quantitative PCR. Results: No significant differences were seen in SNP frequencies at rs 12979860 and rs8099917 in IM and PTLD patients compared to EBV seropositive controls and transplant patients. EBV DNA levels were lower in IM and PTLD patients with CC (a favourable genotype in HCV) at rs 12979860 compared to non-CC genotypes $(p=0.055)$. Acute IM patients with CC had significantly lower levels of EBV DNA in plasma compared to those with non-CC genotypes $(p=0.011)$. Conclusions: Genotype CC
\end{abstract}

may influence anti-viral responses of IFN- $\lambda$, thereby allowing better control of EBV viraemia during lymphoproliferation, particularly in IM.

(c) 2014 S. Karger AG, Basel

Single-nucleotide polymorphisms (SNPs) at rs 12979860 and rs8099917 sites near the interleukin (IL) 28B gene are strongly associated with spontaneous clearance of or a sustained virological response to interferon (IFN) $\alpha$ and ribavirin treatment in hepatitis $C$ virus (HCV) patients [1,2]. Polymorphisms at rs 12979860 are the most important genetic predictors for HCV treatment response and relapse, the most favourable genotype being CC compared to non-CC (CT or TT) [1]. Polymorphisms at rs8099917 are also useful in predicting a sustained virological response, with unfavourable outcomes seen with GG or GT genotypes [2]. IL28B encodes a type III IFN (IFN- $\lambda$ ) which is induced by viral infections and exerts its anti-viral activity by triggering the JAK-STAT pathway, which stimulates IFN-stimulated genes. The anti-viral effects are similar to those of IFN- $\alpha$ and $-\beta[3,4]$. It is postulated that having these SNPs near the IL28B gene may modulate the innate immune responses to HCV infection. Epstein-Barr virus (EBV), a human herpes virus, infects B lymphocytes and establishes a life-long persistent infection in $>95 \%$ of adults worldwide [5]. Primary infection with EBV is as- 


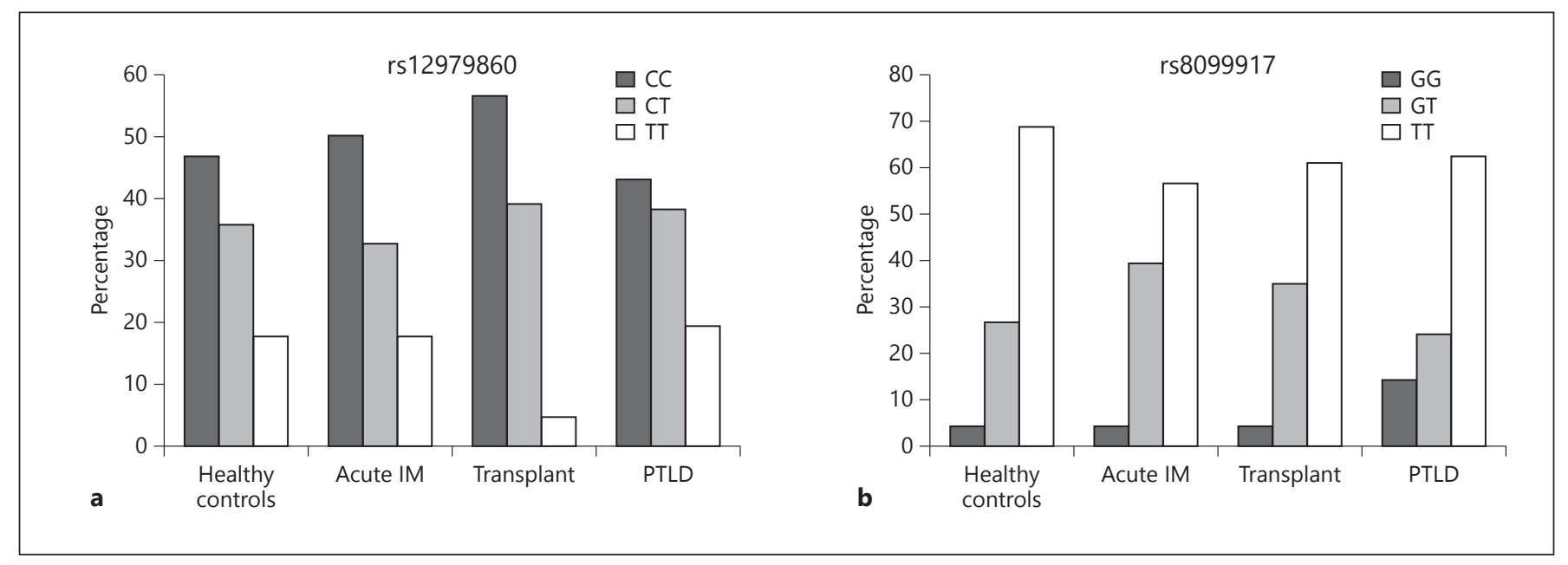

Fig. 1. IL28B gene polymorphisms in study cohorts. Percentages of EBV seropositive healthy controls and acute IM, transplant and PTLD patients with the CC, CT or TT genotype at rs12979860 (a) and the GG, GT or TT genotype at rs8099917 (b).

ymptomatic in the majority of people but can present as an acute self-limiting lymphoproliferative disease known as infectious mononucleosis (IM). Immunocompromised individuals such as transplant recipients can develop EBV-driven post-transplant lymphoproliferative disease (PTLD). It is not clear why some individuals develop symptomatic diseases with EBV and others do not. Studies have identified certain polymorphisms in human leukocyte antigen A loci and in tumour necrosis factor (TNF) a genes that may be associated with the development of IM and PTLD, respectively [6, 7]. It is possible that IL28B polymorphisms can affect the outcome of chronic viral infections such as herpes viruses. This retrospective study was undertaken to determine if the inheritance of 2 of the most investigated IL28B polymorphisms (rs12979860 and rs8099917) was associated with the development of EBV diseases, such as IM and/or PTLD, and with the control of EBV viraemia.

Plasma samples from 135 individuals were retrospectively analysed, including $45 \mathrm{EBV}$ seropositive healthy individuals with serological evidence of past EBV infection (healthy controls), 46 patients with clinically diagnosed and serologically confirmed (IgM and IgG antibodies to EBV viral capsid antigen positive and IgG to EBV nuclear antigen negative) acute IM, 23 adult heart and/or lung transplant recipients without PTLD (transplant patients) and 21 patients who developed biopsy-proven EBV-positive PTLD. All of these patients were enrolled into a previous clinical trial which had ethical approval from the appropriate ethics committee. Acute IM and PTLD samples were collected at the time of clinical, serological and biopsy-confirmed diagnosis. All samples were anonymised at source and given unique identifying numbers, and aliquots of stored plasma samples were used. Genomic DNA was extracted from plasma samples using the QIAsymphony Mini DNA blood extraction kit. Realtime PCR was performed for 2 SNPs within the IL28B locus (C or $\mathrm{T}$ for the rs12979860 site and $\mathrm{G}$ or $\mathrm{T}$ for the rs8099917 site) using a TaqMan allelic discrimination assay, as previously described [8]. EBV DNA was quantitated by a real-time quantitative PCR, as previously described [9]. Statistical analyses between allele frequencies were performed using Fisher's exact test with GraphPad Prism 5. For rs12979860, the CC genotype was compared with non-CC genotypes (CT and TT). For rs8099917, GG and GT (unfavourable) were compared with the TT genotype.

There were a total of 64 males and 71 females in the study, with ages ranging from 1 to 67 years. Average ages for healthy controls and acute IM, transplant and PTLD patients were 22, 21, 40 and 32 years, respectively. Of the 135 patients tested, 66 (49\%) had CC, 48 (35.5\%) had CT and 21 (15.5\%) had TT genotypes at the rs12979860 site. For the rs8099917 site, the overall genotype frequencies were $6 \%$ for GG, $32 \%$ for GT and $62 \%$ for TT. There were no statistically significant differences in the frequency of any genotype for either rs12979860 or rs8099917 in IM and PTLD patients compared to healthy controls and transplant patients, respectively (fig. 1). The percentage of CC at rs12979860 (favourable genotype) was lower (43\%; 9/21) in PTLD patients compared to transplant patients $(57 \% ; 13 / 23)$, but this was not statistically signifi- 


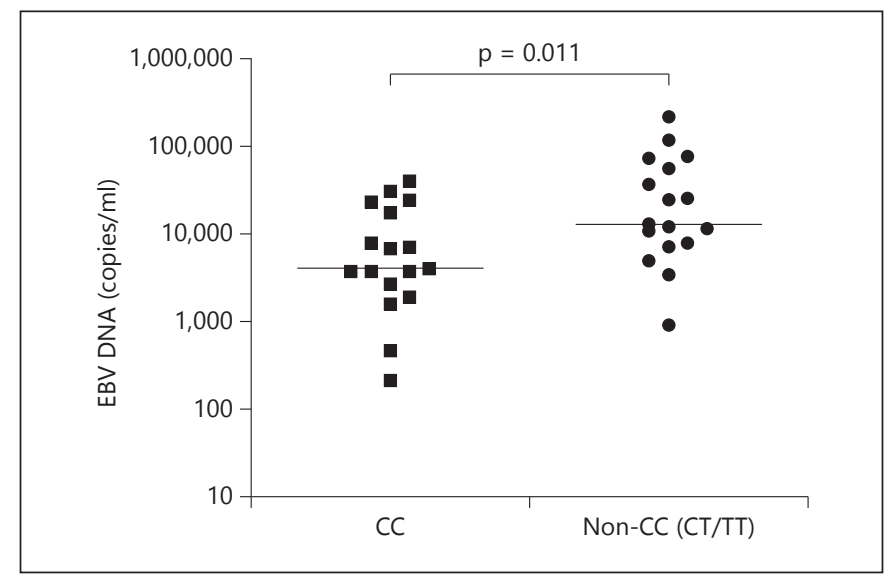

Fig. 2. Comparison of EBV DNA levels in acute IM patients based on CC and non-CC (combined CT and TT) genotypes at rs 12979860 of IL28B. The horizontal black bars denote the median values for each group.

cant $(\mathrm{p}=0.2)$. There was no correlation between the histological types of PTLD and particular SNPs.

EBV DNA levels in plasma were tested and compared in acute IM and PTLD patients based on their IL28B SNPs. Overall, 51 out of $67(76 \%)$ acute IM and PTLD samples tested had detectable EBV DNA (median 6,493 copies/ml, range 103-4,997,550 copies/ml), although no particular genotype was associated with the likelihood of developing EBV DNAaemia. However, IM and PTLD patients with the CC (favourable) genotype at rs12979860 had lower levels of EBV DNA compared to those with non-CC (CT and TT) genotypes (borderline statistical significance, $\mathrm{p}=0.055)$. When analysed separately, 34 of 46 IM samples (74\%) had detectable EBV DNA (median 9,356 copies $/ \mathrm{ml}$, range $213-218,654$ copies $/ \mathrm{ml}$ ). Patients with acute IM with the favourable genotype CC at rs 12979860 had significantly lower levels of EBV DNA in plasma (median 4,038 copies/ml, range 213-40,173 copies/ml) compared to those with non-CC (CT and TT) genotypes (median 12,846 copies/ml, range 913-218,654 copies $/ \mathrm{ml} ; \mathrm{p}=0.011$; fig. 2). These differences in EBV DNA levels were not seen in the PTLD cohort alone or for TT (favourable) versus non-TT (GT and GG) genotypes at rs8099917 (data not shown).

This retrospective study was undertaken to determine whether inheritance of particular polymorphisms at rs12979860 and rs8099917 sites in the IL28B gene could be used as predictive markers for the development of EBV-associated lymphoproliferative diseases such as acute IM and PTLD. The frequencies of polymorphisms for rs12979860 and rs8099917 in our cohorts were similar to those in published data [1] and to that in our own HCV patient cohort, with the $\mathrm{C}$ allele more frequently represented (data not shown). No significant relationship was identified between genotypes of either rs12979860 or rs8099917 polymorphisms for patients with EBV lymphoproliferative diseases (i.e. acute IM and PTLD) compared to seropositive healthy controls and transplant patients, respectively. Others have shown non-correlation of IL28B polymorphisms with outcome in chronic viral infections such as hepatitis B or HIV [10]. CC at rs12979860 was not associated with HBV recovery, resistance to HIV infection or HIV disease progression.

In our study, patients with the CC genotype at rs12979860 had lower levels of EBV DNA in blood compared to those with CT and TT genotypes $(\mathrm{p}=0.055)$. This difference became statistically significant in patients with primary EBV infection and acute IM, as those with the CC genotype within the IM cohort had lower EBV DNA levels compared to those with CT/TT $(p=0.011)$. $\mathrm{CC}$ has been shown to be the most favourable genotype to predict the outcome of natural and IFN- $\alpha$-treated HCV infection. It is possible that the CC SNP near the IL28B gene is helpful in controlling EBV replication during acute infection via IFN- $\lambda$ pathways. Several studies have implicated polymorphisms within cytokine genes, such as IL-10 and its promoter genes, in the risk of developing symptomatic primary EBV infection and its control [11, 12]. Our findings are based on EBV viral load testing on a single sample taken from patients at the time of diagnosis of acute IM and PTLD. It will be interesting to follow EBV levels in sequential samples to establish the further effect of IL28B genotypes in controlling viral replication. We recently showed that the soluble form of CD30, a member of the TNF receptor superfamily, was significantly increased in IM and EBV lymphoproliferative diseases [9]. An association between variant alleles within the TNF- $\alpha$ promoter and TNF receptor promoter regions with the development of PTLD has been shown, indicating that variations within TNF- $\alpha$ loci can be predictive risk factors for PTLD development $[7,13]$. However, several studies reported no association between IFN- $\gamma$ genotype and the development of EBV -positive PTLD in solid organ transplant patients $[13,14]$. Therefore, our findings in IM and PTLD cohorts of a lack of significant differences in polymorphisms of the IL28B gene, which encodes IFN- $\lambda$, may not be surprising. Our sample sizes were too small to draw any conclusion. A larger cohort of patients is needed to determine whether IL28B gene polymorphisms can be predictive markers for the development of EBV-associated lymphoproliferative diseases. 


\section{References}

$>1$ Ge D, Fellay J, Thompson AJ, Simon JS, Shianna KV, Urban TJ, Heinzen EL, Qiu P, Bertelsen AH, Muir AJ, Sulkowski M, McHutchison JG, Goldstein DB: Genetic variation in IL28B predicts hepatitis C treatment-induced viral clearance. Nature 2009;461:399-401.

>2 Suppiah V, Moldovan M, Ahlenstiel G, Berg T, Weltman M, Abate ML, Bassendine M, Spengler U, Dore GJ, Powell E, Riordan S, Sheridan D, Smedile A, Fragomeli V, Müller T, Bahlo M, Stewart GJ, Booth DR, George J: IL28B is associated with response to chronic hepatitis $\mathrm{C}$ interferon-alpha and ribavirin therapy. Nat Genet 2009;41:1100-1104.

$\checkmark 3$ Kotenko SV, Gallagher G, Baurin VV, LewisAntes A, Shen M, Shah NK, Langer JA, Sheikh F, Dickensheets H, Donnelly RP: IFN-lambdas mediate antiviral protection through a distinct class II cytokine receptor complex. Nat Immunol 2003;4:69-77.

4 Sheppard P, Kindsvogel W, Xu W, Henderson K, Schlutsmeyer S, Whitmore TE, Kuestner R, Garrigues U, Birks C, Roraback J, Ostrander C, Dong D, Shin J, Presnell S, Fox B, Haldeman B, Cooper E, Taft D, Gilbert T, Grant FJ, Tackett M, Krivan W, McKnight G, Clegg C, Foster D, Klucher KM: IL-28, IL-29 and their class II cytokine receptor IL-28R. Nat Immunol 2003;4:63-68.
5 Haque T, Crawford DH: Epstein-Barr virus; in Zuckerman AJ, Banatvala JE, Schoub BD, Griffiths PD, Mortimer P (eds): Principles and Practice of Clinical Virology, ed 6. Chichester, Wiley \& Sons, 2009, pp 199-221.

6 McAulay KA, Higgins CD, Macsween KF, Lake A, Jarrett RF, Robertson FL, Williams H, Crawford DH: HLA class I polymorphisms are associated with development of infectious mononucleosis upon primary EBV infection. J Clin Invest 2007; 117:3042-3048.

$\checkmark 7$ McAulay KA, Haque T, Crawford DH: Tumour necrosis factor gene polymorphism: a predictive factor for the development of posttransplant lymphoproliferative disease. $\mathrm{Br} \mathrm{J}$ Cancer 2009; 101:1019-1102.

-8 Montes-Cano MA, García-Lozano JR, AbadMolina C, Romero-Gómez M, Barroso N, Aguilar-Reina J, Núñez-Roldán A, GonzálezEscribano MF: Interleukin-28B genetic variants and hepatitis virus infection by different viral genotypes. Hepatology 2010;52:33-37.

$\checkmark 9$ Haque T, Chaggar T, Schafers J, Atkinson C, McAulay KA, Crawford DH: Soluble CD30: a serum marker for Epstein-Barr virus-associated lymphoproliferative diseases. J Med Virol 2011;83:311-316.
10 Martin MP, Qi Y, Goedert JJ, Hussain SK, Kirk GD, Hoots WK, Buchbinder S, Carrington $\mathrm{M}$, Thio CL: IL28B polymorphism does not determine outcomes of hepatitis B virus or HIV infection. J Infect Dis 2010;202: 1749-1753.

11 Helminen M, Lahdenpohja N, Hurme M: Polymorphism of the interleukin-10 gene is associated with susceptibility to Epstein-Barr virus infection. J Infect Dis 1999;180:496499.

12 Helminen ME, Kilpinen S, Virta M, Hurme M: Susceptibility to primary Epstein-Barr virus infection is associated with interleukin-10 gene promoter polymorphism. J Infect Dis 2001;184:777-780.

13 Babel N, Vergopoulos A, Trappe RU, Oertel S, Hammer MH, Karaivanov S, Schneider N, Riess H, Papp-Vary M, Neuhaus R, Gondek LP, Volk HD, Reinke P: Evidence for genetic susceptibility towards development of posttransplant lymphoproliferative disorder in solid organ recipients. Transplantation 2007; 84:387-391.

14 Thomas RV, McAulay K, Higgins C, Wilkie $\mathrm{G}$, Crawford DH: Interferon gamma (IFNgamma) polymorphism in posttransplantation lymphoproliferative disease. Blood 2005; 106:1502-1503. 